\title{
Stimulating educational growth through vision and self-efficacy: a case study of adult users of English as a foreign language
}

\begin{abstract}
The present study focuses on scrutinising the congruence between the two concepts which are currently at the forefront of the motivational research, namely self-efficacy and the mental representation of a future state which, in the literature, is referred to as vision. To this very end, the first part of the paper offers a concise summary of the theoretical underpinnings behind both constructs. The latter sections of the examination are exploratory and interpretative in their nature and are dedicated to the empirical analysis of the correlation between vision and the sense of personal agency as well as the discussion of the answers stemming from the semi-structured interviews employed for the purpose of the study. The outcomes of the investigation provide satisfactory evidence to account for the presence of a reciprocal interaction between the adopted variables and prompt various noteworthy implications, for example, the positive impact of the notions on inducing a long-term, motivated action, the ability of vision to substitute efficacy beliefs in the initial stages of agency growth, and the stimulating influence of pre-experiencing emotional arousal related to a future state on a student's language proficiency. This, in turn, creates an opportunity for inspiring the motivational gain in a variety of settings, including a foreign language classroom.
\end{abstract}

Keywords: self-efficacy, vision, motivation in an L2 context, performance, behavioural issues, linguistic proficiency.

\section{Introduction}

In recent decades, one may observe a gradually shifting emphasis of the motivational inquiry, with a substantial volume of attention being devoted to affective constructs in efforts to explain and foresee a wide range of human functioning. Although the complexity of human behaviour renders the consensus in this particular area unachievable, it seems that certain variables are somewhat more successful than others in predicting

1 Address for correspondence: Faculty of Philology, University of Rzeszów, al. mjr. W. Kopisto 2B, 35-315 Rzeszów, Poland. E-mail: arekpie122@gmail.com 
behavioural dispositions. As self-efficacy offers robust predictive capabilities, the concept coined by Albert Bandura has been an essential component in theories pertaining to motivation and learning in an array of contexts (Sewell \& St George 2000; Mun \& Hwang 2003; Ansong et al. 2019). The approach towards vision and aspects of imagery, on the other hand, has been recently revisited so that the notions are now seen as more than merely referring to a ubiquitous human ability to use imagination and mental images. The most quintessential perception of vision nowadays is that of a performance facilitator, as adopting a visual perspective in a behavioural intervention framework is believed to moderate the shape of one's motivational experience (Vasquez \& Buehler 2007; Burke et al. 2014). As multipurpose examinations investigating these two variables in combination are currently scarce, this study was initiated in an endeavour to partially ameliorate this particular gap and to expand on the possible correlation between the paramount variables adopted for the inquiry. Supplementary aims set out to the project include scrutinising the influence of vision and personal agency on a person's inclination towards more demanding pursuits and the impact of the former construct on tackling negative rumination related to potential adversities a person may experience in the case of challenging endeavours, such as acquiring language proficiency.

\section{The notion of self-efficacy}

As the nature of human motivation to perform is far from stable and tends to fluctuate throughout time, the debate into the purposiveness of human behaviour has been somewhat dominated by the studies scrutinising the potential of affective variables in temporarily harnessing the daily ebb and flow of engagement (Dörnyei 2000; Turner \& Patrick 2008; Navarro \& Arrieta 2010). In efforts to remedy this particular dilemma and to account for the likelihood of behaviour execution, in the late 1960s, Albert Bandura coined the construct of self-efficacy. Bandura (1994:73) defines personal agency as "people's beliefs regarding their ability to produce designated levels of performance that allow them to exercise a measure of control over events that affect their lives." In its essence, the concept refers therefore to the positive beliefs individuals hold regarding their ability to perform novel tasks leading a person to the achievement of desired goals (Schwarzer \& Warner 2013). Although several decades have passed since Bandura published his seminal work, it appears that the construct unchangeably remains at the forefront of motivational inquiry. This phenomenon is entirely justified bearing in mind the multifaceted nature of self-efficacy; even though the notion was originally devised to explore the possibility of expediting athletic performance, it was soon encompassed within other domains of human existence, including education, addiction treatment, and vocational activities. Expectations upon personal efficacy are believed to leverage a person's conduct in the vicinity of stressful and challenging circumstances by influencing aspects such as decision-making and goal-selecting processes, effort expenditure 
tendencies, strategy selection in the pursuit of desired objectives, and overall tenacity in case of adversities. According to Van der Bij1 \& Shortridge-Baggett (2001: 197), "a favourable judgement of the probability of goal attainment can be a sufficient motivator in itself." A similar view has been expressed by Artino (2012: 82), who claims that "it is not enough for individuals to possess the requisite knowledge and skills to perform a task; they also must have the conviction that they can successfully perform the required behaviour under both typical and challenging circumstances.” On logical grounds, those assured of the sufficiency of their skills and knowledge display more grit in their pursuits and are less disposed towards avoidance behaviours typical for ill-efficacious individuals. Such a positive outlook emboldens a person to approach challenges as opportunities for development, fosters authentic engagement, and aids an individual in counteracting ruminative thoughts stemming from the fluctuating value of motivation. It would also be essential to pinpoint the role of self-efficacy in shaping a person's perception of challenges; the efforts of efficacious people are fuelled by the desire to actualise one's potential realised in seeking mastery through increasing the perceived difficulty of one's endeavours so that initial hardships rarely dishearten a person from performing a task. In stark contrast, people beset by the lack of self-efficacy tend to regard each difficulty as a threat to one's sense of self and are most typically reluctant towards new activities. Following Bandura \& Locke (2003: 88), such individuals "have lower aspirations and tend to lower their goals even further should results be lacking." Instead of attributing failure to insufficient efforts or inept skills and knowledge, ill-efficacious entities dwell on the adverse effects of an action at hand and explain the lack of satisfactory outturns in terms of external adversities. This, in turn, renders such people considerably more prone to feelings of anxiety and discouragement, resulting in task abandonment rather than effort intensification (Bandura 1988; Muris 2002). The delivery of satisfactory performance is therefore limited by negative rumination yielded by the lack of foundational persistence and does not reflect the actual capacity of a person to meet the requirements of a task.

\section{Sources of efficacy beliefs}

Usher \& Pajares (2008: 752) postulate that one's assessment of personal efficacy may emanate from four primary sources and propose the following taxonomy: enactive attainments, vicarious learning, verbal persuasion, and emotional cues. To open with enactive accomplishments, Bandura (1994: 73) alleges that "the most powerful way of efficacy building is through mastery experiences." Specifically, efficacy information is accrued by assessing and interpreting the outcomes of one's past performance and serves as an indicator of one's aptitude to succeed. Prior to defining the final aim of one's pursuits, the analysis of former attainments allows a person to judge the sufficiency of his or her skills in producing favourable results in the case of prospective endeavours. 
As outlined by Reddan (2015: 293), “success builds a robust belief in one's personal efficacy and failure undermines it, especially if failure occurs before a sense of efficacy is well-developed." Notably, the success of building healthy agency beliefs through past accomplishments relies immensely on an individual's interpretation of an experience. Bandura (1994: 74) argues that "some adversities in our pursuits serve a useful purpose in teaching that success requires perseverance." On these grounds, it is possible to assume that should initial difficulties be attributed to insufficient effort rather than an innate inability of a person to produce favourable outcomes, overcoming one's limitation through effort intensification may inspire the growth of self-efficacy and reduce the discouraging impact of numerous challenges a person would experience en route to a desired accomplishment. Moving on to the second origin point from which personal efficacy may stem, the concept of vicarious experience, in its essence, appears to be based on the principles of behaviour modelling. In Bandura's (1994: 75) opinion, "the observation of people similar to oneself producing desired outcomes by sustained effort helps a person in forging the belief that he or she is also capable of mastering similar tasks with comparable effect." Wise \& Trunnell (2001: 269) emphasise the importance of vicarious learning for building efficacy beliefs by stating that such an observation equips an individual with a set of coping strategies helpful in tackling adversities separating a person from reaching one's full potential. It should be accentuated, however, that based on the outcomes of observed behaviour, vicarious experience may either foster or restrain the growth of personal agency. That is, should heightened efforts of a model result in failure rather than accomplishment, an observer would reduce one's expectations in a like manner. Importantly, the effectiveness of modelling in shaping self- efficacy beliefs is partially credited to the perceived degree of likeness between observed behaviour and outcomes a person wishes to produce. Whereas a satisfactory level of similarity would encourage a person to correlate behavioural patterns, the lack of such resemblance is not likely to inspire an action. Turning now to verbal persuasion, the self-perceptions of efficacy may stem from the faith a person's significant others express in one's ability to produce favourable outcomes. Bandura (1994: 78) posits that "verbal reinforcement regarding an individual's ability to master given activities may prompt greater effort when problems arise.” In the presence of taxing circumstances, such an external appraisal of one's mastery within a given domain may counteract dropdowns in motivational energy and supports an individual in sustaining dedication to a cause, provided such feedback is based on a person's authentic capacity to complete a task at hand. Pajares (1997: 23) mentions that "persuaders must cultivate people's beliefs in their abilities and ensure that the envisioned success is indeed achievable." A likewise conclusion has been reached by Reddan (2015: 293), who suggests that "verbal reinforcement is effective in stimulating a sense of personal efficacy if the desired outcome is within realistic boundaries." Conversely, insincere encouragement may possess a 
ruinous impact on the shape of one's agency beliefs once the unrealistic appraisal is followed by unsatisfactory outcomes. The majority of studies are consistent as to the claim that although such reinforcement should be in accord with a person's capacity to succeed, the most useful efficacy judgements are those that slightly exceed a person's capabilities, as this modest overestimation increases effort and persistence during difficult times (Hattie \& Timperley 2007; Artino 2012). The last source of agency beliefs identified by Bandura seeks to explain the causality of human behaviour in terms of emotional cues and pertains to the influence of somatic messages prompted by physiological and emotional experiences. Damasio et al. (1991: 222) contend that emotional reactions to a task, to a large margin, shape decision-making processes and supply suggestions about the expected success or failure of an undertaking. Whereas stress reactions and negative rumination during demanding pursuits are most typically associated with signs of vulnerability, positive emotionality emanating from the possibility to perform a task encourages persistence and fuels subsequent efforts. Bandura (1997: 37) stresses that "it is not the sheer intensity of a state but rather a human interpretation of an experience that influences our actions." With this in mind, reducing the extent to which negative thoughts influence one's self-perceptions may contribute to fostering performance and building sustainable beliefs in one's agency.

\section{Vision and mental imagery}

Much research work has been devoted to accommodating the notion of vision amongst the contemporary strands of the motivation inquiry and the concept is now considered as one of the contributory factors in inducing long-term, motivated behaviour. Essentially, the construct of mental imagery pertains to channelling one's present behaviours towards the accomplishment of a future target (Muir \& Dörnyei 2013: 359). Kosslyn et al. (2006: 4) provide a more complex definition of the term and postulate that vision is "the imitative representation created when perception is present, but the corresponding stimulus is not actually being perceived.” The consensus view nowadays is that a vision experience operates on neural mechanisms identical to those of a real event and produces analogous emotional loading. This very sensory stimulation, in turn, substantiates the motivational potential of vision; by forming an illusion of a real event, vision operates within the constraints of reality so that the human brain perceives an experience as a genuine opportunity for action (Cox 2012: 12). The combination of vivid imagery with a fracture of positive emotional loading one would experience once the final goal is attained provides an individual with the impetus to produce a desired outcome in the real world. The degree to which a vision was internalised should also be accentuated here, as different motivational aspirations involve various strategies in the pursuit of outstanding performance. Specifically, in the case of demanding endeavours, having a personalised target of one's own would not suffice in reaching the optimal 
version of self. Henry et al. (2015: 332) assert that "certain objectives, especially those requiring long-term engagement, cannot be achieved without supplying a goal with the positive sensory stimulation stemming from a vision of a future self." Individuals who experienced positive emotionality related to a future accomplishment are more inclined to work towards an objective and, as a natural consequence, display more eagerness to intensify their efforts in the strive to produce a desired outcome. Holmes et al. (2016: 257) suggest that "altering one's emotionality is a more sufficient route to trigger behaviour change, as cognitive processing of behaviour change interventions, which is quite frequently based on guidance rather than a proper plan for action, does not guarantee the emergence of motivation.” Dörnyei et al. (2014: 24) add that the role of vision is essential not only for triggering the initial motivation but also for regulating its value throughout an experience. By encouraging people to pre-experience future planned behaviours and the accompanying emotional consequences, it is possible to inspire the immense flow of motivational energy. Thus, harnessing the power of vision and, then, using it as an apparatus to inspire motivational gain would be of extreme aid in any domain of human functioning where exceptional tenacity is required, with mastering a foreign language as one of the most notable examples. On an additional note, the review of the relevant literature reveals that the notions of goal and vision are, on a frequent basis, used interchangeably to label one's future aspirations. Despite the presence of some conceptual similarities, however, vision should not be mistaken with a goal; whereas the former refers to a highly desired imagination of a future state enriched by tangible, sensory images, a goal is a target one aims for when engaging in an activity. Likewise, vision is rarely seen as a solitary trigger of motivated action but rather as an amplifier of one's engagement in the pursuit of personally relevant targets (Renner et al. 2019).

\section{Elements of vision in motivation theories}

In the last decades, the concept of vision and the theories of self-imagery have received a considerable amount of attention. In terms of examining the impact of visualisationbased techniques on human existence, the Possible Selves theory created by Markus \& Nurius is, by many, considered to be one of the most preeminent. Markus \& Nurius (1986: 964) suggest that each person possesses three possible versions of self, namely what they might become, what they are afraid of becoming, and the desired self. Each motivated behaviour is, in fact, driven by the desire to reduce the perceived dichotomy between the current state of skills and knowledge and one's most optimal version. An actor in such a motivational structure focuses his or her efforts on diminishing the aforementioned discrepancy, while the sensory experience related to the perception of this disparity serves as the fuel for motivational impetus. Importantly, van der Helm (2009: 99) claims that in order to inaugurate the motivational potential of vision, "the 
mental representation cannot concern just any possible self; rather, it should be the most desirable one." Provided an individual displays a desire for a deliberate change in one's future, vision is capable of channelling a person's actions towards the accomplishment of an end-goal.

Moving on to the L2 Motivational Self System, the conceptualisation appears to be Dörnyei's attempt to extend the aforementioned theory on the grounds of Second Language Acquisition. In their efforts to elaborate on students' motivational experiences, Muir \& Dörnyei (2013: 360) identify two primary constituents of the conceptualisation, namely the Ought-to L2 Self and the Ideal L2 Self. With regard to the former, an individual en route to accomplishing the full extent of one's abilities focuses on systematic improvement of skills and knowledge so that they would be more akin to those of a target model. Quite the opposite attitude, however, may be observed in the case of people pursuing the Ought-to L2 Self. In the view of Dörnyei \& Ushioda (2009:29), the approach concerns "the set of attributes one believes to be critical to meet expectations and to avoid possible adverse outcomes.” Instead of directing one's energy at acquiring mastery within a given domain, such entities were found to concentrate on minimising the risk of being ridiculed through insufficient performance, with avoidance behaviours being the most typical reaction towards prospective adversities. Surprisingly, although the Ideal L2 Self would be desirable in a foreign language classroom, depending on a motivational objective one embraces as his or her own, both models are capable of inspiring the motivational gain.

Beyond any doubt, exploiting the regulatory force of motivation or, rather, preventing its level from fluctuating, would be beneficial for performance regardless of the context. Dörnyei \& Kubanyiova (2014: 10) propound the view that incorporating vision in a motivational framework allows for exercising such a measure of control over motivation in the case of distal pursuits and, in consequence, should be considered as "the motivational force of the highest order." This is not to say, however, that the mere inclusion of imagery techniques guarantees the emergence of motivated action. Muir \& Dörnyei (2013:358) state that "by combining a clear vision with a matching structure, it is possible to consciously create a motivational surge of energy and, then, focus this drive towards a specific target." Considering that both features were embodied in the novel conceptualisation of Directed Motivational Currents ${ }^{2}$, the proposal formulated by Dörnyei and his colleagues has quickly received recognition in recent years. Muir \& Dörnyei (2013: 358) observe that a DMC emerges when "a structured pathway is set up towards a vision, reinforcing the momentum throughout the way to an explicit point in the future." Such a framework is believed to be entirely self-propelling, provided a vision of a desired

2 For a more detailed discussion concerning the Directed Motivational Currents theory, see Dörnyei et al. (2016). 
state is completely internalised and the corresponding emotional stimulus provides cohesion for one's efforts. This, in turn, opens an opportunity for creating a more stable environment for performance, allowing a person to achieve results beyond standard cases of motivation. The validity of the structure was confirmed by a number of empirical studies (Henry et al. 2015; Ghanizadeh \& Jahedizadeh 2015; Pietluch 2018).

\section{Research rationale and hypotheses}

The influence of personal assessment of one's efficacy on human performance in a variety of settings is rather well-investigated (Pajares 1996; Vancouver \& Kendall 2006; Meral et al. 2012). The studies in question yielded sufficient evidence to account for the claim that a high sense of agency indeed contributes to producing favourable results, especially in the case of demanding endeavours. Bearing the scope of this research project in mind, it would be important to note that the recent empirical investigations into the impact of the notion rendered positive results also in the context of academic achievement (Lane \& Lane 2001; Zajacova et al. 2005; Yokoyama 2019; Domenech-Betoret et al. 2017). Vision, on the other hand, currently experiences somewhat of a renaissance and has, yet again, become one of the central variables in motivational research, with its predominant application in the field of language learning (Muir \& Dörnyei 2013; Henry et al. 2015; Dörnyei et al. 2016). On the basis of the theoretical discussion, one can observe that not only are the two variables integral parts of motivated behaviour but they also share a large volume of conceptual similarities. For this reason, it is possible to assume that these two factors are mutually dependent, i.e. well-developed efficacy beliefs are imperative for the emergence of a clear-cut vision of a future self. Although some efforts have been made to explore the correlation between the variables, the review of the related literature revealed the lack of multipurpose examinations combining these two concepts in the context of L2 learning. On these grounds, it is possible to move towards the formation of the following research hypotheses:

1. There exists an equivalence between a positive perception of one's coping abilities and the ratio at which a well-established vision of a future self occurs;

2. A high value of self-efficacy and the ability to pre-experience outcomes of a future state facilitate achievement by rendering individuals more eager to visualise themselves as capable of embracing longitudinal and challenging pursuits and limiting the occurrence of negative rumination, also in the context of language learning

\subsection{Apparatus}

Participants' self-efficacy beliefs were explored through a standardised version of the General Self-Efficacy scale derived from Schwarzer \& Jerusalem (1995). The instrument consists of 10 forced-answer statements and responses are recorded on a 5-point Likert 
continuum $^{3}$, with grades ranging from 1 (strongly disagree) to 5 (strongly agree) and yielding a total score between 10 and 50. The items included in the test are positively worded, with the most typical statement being "Thanks to my resourcefulness, I can handle unforeseen situations." The paramount intent of the tool is to measure different facets of agency beliefs, including the degree of resourcefulness, effort expenditure tendencies, and a person's attitude towards the sufficiency of one's skills to accomplish a task at hand. Leaving the tool's flexibility in measuring various aspects of personal agency aside, the test was also chosen due to its large corpus of results, with the mean score of Cronbach's alpha ${ }^{4}$ oscillating around 0.88 for the adults aged 20 to 50 . Criterionrelated validity of the GSEs was documented in several correlation studies which rendered positive coefficients with academic buoyancy (Carroll et al. 2009; Martin et al. 2010), resilience (Taylor \& Reyes 2012; Sagone \& De Caroli 2014), and vocational pursuits (Betz \& Voyten 1997; Creed \& Prideaux 2001). The internal consistency of the instrument in this particular research project was reflected in the Cronbach's alpha of 0.85 .

In order to expand on the individual cases of vision amongst the respondents, a variation of the DMC Disposition Questionnaire stemmed from Muir (2016) was utilised. By combining both open and multiple-choice questions, the instrument explores various realms of visionary experience, including the duration of motivated behaviour, the degree to which a vision is personalised, and the state of efficacy beliefs prior and during a motivational episode. In a manner similar to the preceding questionnaire, in the multiple-choice section of the tool, participants are requested to record their agreement along a 5-point Likert-type response format, with the answers ranging from 1 (strongly disagree) to 5 (strongly agree). Previous studies demonstrated a high internal consistency of the instrument, with Cronbach's alpha of 0.84 . The sample employed for the purpose of this study produced a similar result, with the score of Cronbach's alpha oscillating around 0.82 for the entire project. The remaining questions were interpreted on several separate occasions, yielding a substantial number of conclusions for further empirical investigation. Additionally, in the second stage of the research project, individual semi-structured interviews were carried out in an effort to investigate the respondents' visionary experiences in-depth. During each interview, the participants were requested to focus on the implications their vision may have had on initiating their motivational experience, preferably in the L2 setting.

\footnotetext{
3 For more information on the design and interpretation of Likert scales, please see Allen, Elaine, and Christopher Seaman. 2007. Likert Scales and Data Analyses. Quality Progress: 64-65.

4 Cronbach's alpha is a standard test used to estimate the reliability of a composite score and it is the most predominantly applied technique in assessing the internal consistency of multiple-question Likerttype scales.
} 


\subsection{Participants and sampling}

The data collection process took place between April and July 2018 and the initial sample of this study was composed of 148 adult users of English as a foreign language currently employed at one of the major corporate businesses in Rzeszow. Due to the nature of their work, all of those surveyed employ the language for vocational purposes on a daily basis. In efforts to ensure the language homogeneity of the group, at the time of the inquiry, all of the respondents were pursuing a Bachelor's degree in English Philology at both private and public universities in Rzeszow. Of the total population, 79 participants were female and 69 were male. As far as the age factor is concerned, the subjects ranged from 18 to 45; however, the vast majority of the respondents marked their belonging to the 21-30 bracket (77.7\%). The subjects were assured their participation was to be voluntary and that it would have no impact on their final grade. The basic aims of the study were explained and, then, the participants were provided with the previously described psychometric tests to complete. Although both tools utilised for the purpose of the study included straightforward instructions, prior to the actual procedure, the guidelines were also reinforced verbally. To calculate the results of the questionnaires, a typical approach to the interpretation of the Likert-Type scales was adopted. Following this stage, the outcomes were subject to a standard battery of correlational tests to explore the potential existence of a relationship between the primary variables.

\subsection{Results and discussion}

Prior to addressing the paramount hypotheses of the present research project, the quantitative data yielded by the instruments was put under scrutiny. The findings of the GSEs test were somewhat surprising; the average score for the total population was 34.12 and would suggest that, for the majority of study's respondents, a robust belief in their own agency was lacking. Turning now to the exploration of individual vision experiences, one has to bear in mind that not every case of motivated behaviour bears the marks of a true vision so that the answers stemming from the second instrument had to be examined for the presence of features such as high degree of internalisation and the emotional stimulation related to a future state. On these grounds, a sample of 72 cases relevant for the investigation was created, constituting nearly one half of the entire research group (48.65\%).

As the basic aim of the study was to examine the nature of the correlation between vision and the value of self-efficacy, it was recommendable to, once again, scrutinise the efficacy beliefs amongst the participants who reported experiencing the sensory stimulation corresponding to a future state. In agreement with the study's presumptions, the average GSEs score for the group was substantially higher in comparison to the entire population included in the project; the arithmetic mean of 46.37 points indeed indicates a well-established sense of personal agency. To explore the possible relationship 
between high self-efficacy and vision occurrence, and address the first research hypothesis, Spearman's rank correlation coefficient was applied. The choice of the correlation method was not coincidental and was somewhat dictated by the results of the ShapiroWilk normality test, which revealed for the data to be far from typical in a normally distributed population. Table 1 below offers a concise summary of the outcomes of the aforementioned test.

Table 1. Shapiro-Wilk normality test

\begin{tabular}{|l|l|l|l|}
\hline & \multicolumn{2}{|l|}{ Shapiro-Wilk } & Relevance \\
\cline { 2 - 4 } & Statistics & Df & .025 \\
\hline $\begin{array}{l}\text { General Self- } \\
\text { Efficacy (1-5) }\end{array}$ & .953 & 72 & .000 \\
\hline $\begin{array}{l}\text { Vision occurrence } \\
(1-5)\end{array}$ & .789 & 72 & \\
\hline
\end{tabular}

The outturns of Spearman's rank correlation coefficient seem to render the quantitative hypothesis of the project justifiable; the results of the test gathered in Table 2 below provide sufficient evidence to support the claim that such a correlation indeed exists. The results were also found to be relevant from the statistical standpoint $(p<0,01)$, validating a reciprocal nature of the relationship between the variables. On these grounds, it is possible to draw an unyielding conclusion that, in the population under scrutiny, the value of self-efficacy permeates decision-making processes and contributes to developing a well-established vision of a future self which, in turn, allows a person to embrace more distal and demanding objectives.

Table 2. Spearman's rank correlation coefficient

\begin{tabular}{|l|l|l|}
\hline \multicolumn{2}{|l|}{} & Vision occurrence $(1-5)$ \\
\hline \multirow{3}{*}{$\begin{array}{l}\text { level of General } \\
\text { Self-Efficacy (1-5) }\end{array}$} & Spearman's correlation & $.712^{\star *}$ \\
\cline { 2 - 3 } & Correlation coefficient & .000 \\
\cline { 2 - 3 } & N & 72 \\
\hline
\end{tabular}

Even more importantly, similar conclusions were reached following the analysis of the answers provided during the semi-structured interviews employed for the purpose of this investigation. In the section below, the focus shall remain on exploring and interpreting some of the opinions disclosed by the respondents.

Beyond any doubt, juggling demands of higher education with vocational pursuits is highly exacting an endeavour. When enquired about what stimulated participant $\mathrm{X}$ to 
embrace such a challenging schedule, she mentioned her lifelong dream has been to become an academic teacher. Due to the requirements of the position, she is currently combining a full-time job with pursuing her Bachelor's degree in English Philology:

My current employer provides services to companies all around the world, so I am working in a 24/7 environment. I am a professional and I do not allow my academic pursuits to interfere with my performance at work. I sometimes struggle with finding the time to study, however, I am still one of the best students in my group. My degree makes me feel more competent at work but, at some point, I would like to focus on the academic aspect entirely. Although it can be very hectic at times, I often imagine myself working at the university and I know it will be worth it in the long run.

Needless to say, the respondent is exceptionally motivated to accomplish her goal. Although her current lifestyle prompts all sorts of difficulties related to an effective combination of academic and vocational pursuits, she appears to be convinced that, once she reaches the desired version of self, the rewarding outcomes will by far outweigh the effort invested in achieving the target. Bearing in mind that human motivation is highly tumultuous in its nature, in the sense that it rarely remains stable throughout time, it appears that the application of mental imagery related to the desired occupation aids the participant in harnessing the turmoil of motivational energy. In this case, the respondent's will to achieve is enriched by a tangible vision and, as such, her level of motivation does not seem to require particular volitional control. This, in turn, lends support to the claim that, when fully internalised, a vision is capable of evoking positive emotional stimulation akin to this of a real event. Even though the participant admitted experiencing some issues in managing such a hectic lifestyle, with most of them being of organisational nature, the sensory arousal related to the final state remedies the respondent's occasional apathy. In the vicinity of temporal dropdowns of motivation, the participant focuses on the final outcome of her current pursuits; her academic and occupational activities serve as means of boosting her linguistic proficiency so that, at some point in the future, she will be well-equipped to utilise the language in question at the academic level. In fact, the mental imagery related to this specific experience ongoingly stimulates the participant to further improve the state of her language capacities. Additionally, the ability to effectively prioritise the demands of her current lifestyle provides the participant with a sense of achievement and, consequently, contributes to developing well-anchored agency and propels participant's belief that the envisioned success is indeed achievable. On this basis, one may formulate the conclusion that the subject's sense of efficacy is stemming from mastery experience, as being both occupationally and academically active allowed the respondent to develop a highly personalised framework for counteracting cases of amotivation. 
In stark contrast to the majority of respondents, the story recalled by participant $\mathrm{Y}$ concerns the objective that had been already accomplished. When requested to elaborate on the most intense language experience, the subject described the situation when she was presented with the opportunity to run a large-scale training programme for her company in Spain:

At first, I was really excited. I have always been an eager traveller and this seemed to be a fantastic opportunity to experience something new. Although English is the primary language of communication in our company, the condition was I had to improve my Spanish to a communicative extent, allowing more effective interaction with colleagues in Spain. With the deadline approaching and only a couple of months left till the project delivery date, I became extremely anxious as to whether I could learn a moderately new language in such a short time. As the project was extremely important to me, I began to imagine what it would feel like to live in Spain and it really helped! I wanted to be busy with the language all the time and was soon able to communicate with my fellow students.

The analysis of the above account clearly indicates that despite being well-aware of the challenges involved in the pursuit, with overcoming the language barrier being the most notable one, throughout the experience, the participant remained focused on the potential favourable outcomes of her endeavour. In this case, the emergence of a well-defined vision of a future state may be seen as a triggering factor of the respondent's motivational experience, allowing the subject to exercise control over the initial negative rumination stemming from the task difficulty. It should also be accentuated here that, once the goal was imbued with a properly internalised vision, the participant experienced positive emotionality of high intensity which fuelled her efforts in an ongoing fashion and, ultimately, rendered the desired result attainable. The increased volume of language exposure stemming from that positive outlook, in turn, significantly boosted the rate at which the participant acquired the communicative command of the language in question. With this in mind, it is possible to assume that a personalised vision of one's future self not only does stimulate a person to embrace more demanding pursuits, regardless of a context, but also supports an individual in both developing and sustaining a feeling of competence by enhancing one's agency beliefs with the fracture of emotional stimulation a person would experience once the final state is reached. Even though on the basis of the theoretical discussion, mental imagery may be understood as an efficacy facilitator rather than a trigger of motivational impetus, the analysis of the participant's experience seems to validate the claim that vision is capable of initiating the growth of agency in the instances when well-developed beliefs as to one's capacity to succeed are lacking. For this reason, the intensity of a motivational experience augmented by elements of mental imagery might be indeed seen as beyond standard 
cases of motivation human beings experience, encouraging stellar performance even in the case of highly demanding endeavours.

To complete the discussion, it would be recommendable to pinpoint certain salient elements that indicate the vision experiences described by the study participants could be indeed deemed as fully-fledged mental images pertaining to the formation of future self-identity. One of the most fundamental criteria in assessing whether one's aspirations reflect a properly internalised vision of self is the presence of an apparent dichotomy between a person's current state and the one that an individual is opting to achieve in the future. Following Dörnyei (2014: 9), the lack of such discrepancy renders a person unable to activate sufficient effort and, thus, is not likely to ignite deliberate action to change one's present condition. In all cases examined, it was possible to observe an evident disparity between participants' current and ideal selves; the respondents possessed elaborate and vivid images of their future versions which were substantially different from their pre-vision states. Furthermore, the participants emphasised that the vision experiences were tangible in the sense that one's efforts directed at the specific end-state were augmented through experiencing sensory stimulation akin to the one a person would experience once the final attainment was produced. This would, yet again, substantiate the claim that the application of mental imagery encourages higher effort expenditure in the pursuit of the desired version of self.

The plausibility of one's future self-image is another essential prerequisite of a vision experience. Although the pursuits of our respondents, quite frequently, involved numerous challenges requiring the students to completely reorganise their daily routines to better match the requirements of a task, the presence of adequately articulated vision strengthened the participants' beliefs that the end-goals were indeed within their reach. The goals the respondents opted for were not comfortable and required the students to energise plenty of effort to successfully perform the activities conducive to the actualisation of the potential of an entity. The existence of such procedural strategies acted as a scaffolding for their motivational interventions and ensured that the participants remained dedicated to their aspirations despite the presence of potential demotivators distracting them from pursuing the ideal self. From the educational perspective, one may postulate that whilst the process of learning a foreign language is not immune to the influence of affective variables capable of hampering a student's progress, the presence of a true vision allows a learner to focus on the ultimate destination and, resultatively, trigger the persistence required to achieve one's full potential. 


\section{Concluding remarks and recommendations for future research}

The main rationale behind this paper was to explore the nature of the correlation between positive self-appraisals of efficacy and the occurrence of mental imagery related to reaching a highly desired version of a future self. Whilst the results of the quantitative aspect of the investigation render the existence of such a relationship valid and the outcomes of the GSEs test indeed favour the image of the participants as highly efficacious entities, there is a rather peculiar observation to be made. That is, some individuals included in the study displayed a strong sense of efficacy prior to the emergence of their vision experience and, during the event, the amount of trust they placed in their agency would not fluctuate. On this basis, one may assume that the confidence those individuals possess for their competence serves as the incentive to internalise a goal regardless of a setting and a task difficulty. This motivational scaffolding is further reinforced by positive emotional arousal stemming from pre-experiencing the rewarding consequences of a future state, ensuring individuals in the pursuit of such targets would remain dedicated to a cause. On the other hand, it is also possible to identify cases where adopting a new challenge inspired the sharp growth of personal agency beliefs. By focusing on the positive emotionality stemming from enhancing a goal with mental visualisation of a future state, the participants were capable of sufficiently overcoming negative rumination related to the potential adversities their endeavours may yield.

Even more interestingly, it is possible to identify instances when vision may be seen as a sole trigger of a motivational experience, allowing a person to adequately counteract daily ebb and flow of motivated action. Although set in entirely different contexts, all of the examples included in the research share one critical similarity - it transpires that the positive emotionality emanating from the inclusion of vision element increases participants' eagerness to actualise one's potential through embracing more demanding tasks, also in the context of developing language proficiency. Supplementing one's pursuits with the elements of mental imagery encourages tenacity in overcoming personal limitations related to a task at hand and, consequently, provides a person with more opportunities to seek mastery in a given domain. On an additional note, even though individual cases differ markedly, the positive impact of self-efficacy on performance within any realm of human existence is easily discernible; well-anchored agency beliefs embolden people to set adequately tailored action plans required to achieve their aspirations and boost persistence in an ongoing fashion, whereas the opportunity to reduce the discrepancy between the current state and the most optimal version of self provides our subjects with a unique sense of improvement, favouring the perception of a person as an entity capable of attaining even highly troublesome objectives. This being said, we can put forward an assumption that the relationship between the variables is highly reciprocal in its nature; both notions were found advantageous in tackling taxing 
circumstances so that a proper combination of vision and self-efficacy may be sufficient in yielding a motivational surge of high intensity which would outclass standard cases of motivation. From the educational standpoint, guiding students in enriching their targets with elements of mental imagery as well as incorporating efficacy building techniques in the strive to inspire highly motivated action may contribute to the overall shape of language competence by supporting a person in sustaining dedication to the cause, which is of tremendous importance in the case of time-consuming pursuits such as learning a foreign language.

Beyond any doubt, harnessing the motivational power of vision and self-efficacy can be of extreme help in addressing behavioural issues. By combining appropriately crafted, tangible visualisation with a matching motivational scaffolding, that would gradually increase one's awareness concerning the coping competence, it is possible to inspire the impetus that would by far surpass the standard cases of motivation. Henceforth, comprehending the exact nature of the relationship between these two concepts may provide those concerned with the field with a crucial tool in developing motivational interventions. This knowledge could then be put into practice in various realms of human functioning, for instance, education or addiction treatment. Although the present analysis provides compelling evidence for the congruence between the variables, it would also be interesting to expand on the areas such as the correlation of self-efficacy and vision with other affective variables or the techniques of inducing the motivational gain on the classroom level. Overall, the most important conclusion to be drawn here is that larger-scale, longitudinal investigations are most definitely required to explore the impact of the factors on various aspects of human existence so that the potential of vision and self-efficacy may be better channelled to suit motivational interventions in more context-specific domains, for instance, a foreign language classroom.

\section{References}

Allen, E. \& Seaman, C. 2007. Likert scales and data analyses. Quality Progress 40: 64-65. Ansong, D., Eisensmith, S., Okumu, M. \& Chowa, G. 2019. The importance of self-efficacy and educational aspirations for academic achievement in resource-limited countries. Journal of Adolescence 70: 13-23.

Artino, A. R. 2012. Academic self-efficacy: from educational theory to instructional practice. Perspectives on Medical Education 2: 76-85.

Bandura, A. 1988. Self-efficacy conception of anxiety. Anxiety Research 1: 77-98.

Bandura, A. 1994. Self-efficacy. In: V. S. Ramachaudran (ed.), Encyclopaedia of Human Behaviour, 71-81. New York: Academic Press.

Bandura, A. 1997. Self-efficacy: The Exercise of Control. New York: Freeman.

Bandura, A. \& Locke, E. A. 2003. Negative self-efficacy and goal effects revisited. Journal of Applied Psychology 88: 87-99. 
Betz, N. E. \& Voyten, K. 1997. Efficacy and outcome expectations influence career exploration and decidedness. Career Development Quarterly 46: 179-189.

Burke, A., Shanahnan, C. \& Herlambang. E. 2014. An exploratory study comparing goaloriented mental imagery with daily to-do lists: Supporting college students success. Current Psychology 33: 20-34.

Carroll, A., Houghton, S., Wood, R., Unsworth, K., Hattie, J., Gordon, L. \& Bower, J. 2009. Self-efficacy and academic achievement in Australian high school students: The mediating effects of academic aspirations and delinquency. Journal of Adolescence 32: 797817.

Cox, R. H. 2012. Sports Psychology: Concepts and Applications. New York: McGraw-Hill.

Creed, P. A., Prideaux, L.-A. 2001. Career maturity, career decision-making self-efficacy and career indecision: A review of the accrued evidence. Australian Journal of Career Development 10: 7-12.

Damasio, A. R., Tranel, D. \& Damasio, H. C. 1991. Somatic markers and the guidance of behaviour: Theory and preliminary testing. In: H. S. Levin, H. M. Eisenberg \& A. L. Benton (eds.), Frontal Lobe Function and Dysfunction, 217-229. New York: Oxford University Press.

Domenech-Betoret, F., Abellan-Rosello, L. \& Gomez-Artiga, A. 2017. Self-efficacy, satisfaction, and academic achievement: The mediator role of students' expectancy-value beliefs. Frontiers in Psychology 8: 1180-1193.

Dörnyei, Z. 2000. Motivation in action: Towards a process-oriented conceptualisation of student motivation. British Journal of Educational Psychology 70: 519-538.

Dörnyei, Z. 2014. Future self-guides and vision. In: K. Csizer \& M. Magid (eds.), The Impact of Self-Concept on Language Learning, 7-18. Bristol: Multilingual Matters.

Dörnyei, Z. \& Ushioda, E. 2009. Motivation, Language Identity and the L2 Self. Buffalo: Multilingual Matters.

Dörnyei, Z. \& Kubanyiova, M. 2014. Motivating Learners, Motivating Teachers: Building Vision in the Language Classroom. Cambridge: Cambridge University Press.

Dörnyei, Z., Muir, C. \& Ibrahim, Z. 2014. Directed Motivational Currents: Energising language learning through creating intense motivational pathways. In: D. Lasagbaster, A. Doiz \& J. M. Sierra (eds.), Motivation and Foreign Language Learning, 9-29. Philadelphia: John Benjamins.

Dörnyei, Z., Henry, A. \& Muir, C. 2016. Motivational Currents in Language Learning: Frameworks for Focused Interventions. New York: Routledge.

Ghanizadeh, A. \& Jahedizadeh, S. 2015. De-motivators and their association with burnout and language achievement in an Iranian EFL context. Journal of Teaching Language Skills 7: 61-85.

Hattie, J. \& Timperley, H. 2007. The power of feedback. Review of Educational Research 77: 81-112. 
Henry, A., Davydenko, S. \& Dörnyei, Z. 2015. The anatomy of Directed Motivational Currents: Exploring intense and enduring periods of L2 motivation. The Modern Language Journal 99: 329-345.

Holmes, E. A., Blackwell, S. E., Burnett Heyes, S., Renner, F. \& Raes, F. 2016. Mental imagery in depression: Phenomenology, potential mechanisms, and treatment implications. The Annual Review of Clinical Psychology 12: 249-280.

Kosslyn, S. M., Thompson, W. L. \& Ganis, G. 2006. The Case for Mental Imagery. New York: Oxford University Press.

Lane, J. \& Lane, A. M. 2001. Self-efficacy and academic performance. Social Behaviour and Personality. An International Journal 29: 687-693.

Markus, H. \& Nurius, P. 1986. Possible selves. American Psychologist 45: 954-969.

Martin, A. J., Colmar, S. H., Davey, L. A. \& Marsh, H. 2010. Longitudinal modelling of academic buoyancy and motivation: Do the 5Cs hold up over time? British Journal of Educational Psychology 80: 473-496.

Meral, M., Colak, E. \& Zereyak, E. 2012. The Relationship between self-efficacy and academic performance. Procedia - Social and Behavioural Sciences 46: 1143-1146.

Mun, Y. \& Hwang, Y. 2003. Predicting the use of web-based information systems: selfefficacy, enjoyment, learning goal orientation, and the technology acceptance model. International Journal of Human-Computer Studies 59: 431-449.

Muir, C. 2016. The dynamics of intense long-term motivation in language learning: Directed Motivational Currents in theory and practice. Unpublished $\mathrm{PhD}$ thesis, University of Nottingham.

Muir, C. \& Dörnyei, Z. 2013. Directed Motivational Currents: Using vision to create effective motivational pathways. Studies in Second Language Learning and Teaching 3: 357-375.

Muris, P. 2002. Relationships between self-efficacy and symptoms of anxiety disorders and depression in normal adolescent sample. Personality and Individual Differences 32: 337-348.

Navarro, J. \& Carlos, A. 2010. Chaos in human behaviour: The case of work motivation. The Spanish Journal of Psychology 13: 244-256.

Pajares, F. 1996. Self-efficacy beliefs in academic settings. Review of Educational Research 66: 543-578.

Pajares, F. 1997. Current directions in self-efficacy research. In: M. Maehr \& P. Pintrich (eds.), Advances in Motivation and Achievement, 1-49. Greenwich: JAI Press.

Pietluch, A. 2018. Extraordinary motivation or a high sense of personal agency: The role of self-efficacy in the Directed Motivational Currents theory. New Horizons in English Studies 3: 45-56.

Reddan, G. 2015. Enhancing student's self-efficacy in making positive career decisions. Asia-Pacific Journal of Cooperative Education 16: 291-300. 
Renner, F., Murphy, F. C., Ji, J. L., Manly, T. \& Holmes, E. A. 2019. Mental imagery as a "motivational amplifier" to promote activities. Behaviour Research and Therapy 114: 51-59. Sagone, E. \& De Caroli, M. E. 2014. Resilience and psychological well-being: Differences for affective profiles in Italian middle and late adolescents. Revista INFAD de Psicologia 1: $149-160$.

Schwarzer, R. \& Jerusalem, M. 1995. Generalized self-efficacy scale. In: J. Weinman, S. Wright \& M. Johnston (eds.), Measures in Health Psychology: A User's Portfolio. Casual And Control Beliefs, 35-37. Windsor: NFER-NELSON.

Schwarzer, R. \& Warner, L. M. 2013. Perceived self-efficacy and its relation to resilience. In: S. Prince-Embury \& D. H. Saklofske (eds.), Resilience in Children, Adolescents, and Adults. Translating research into practice, 139-150. New York: Springer.

Sewell, A. \& St George, A. 2000. Developing efficacy beliefs in the classroom. Journal of Educational Enquiry 2: 58-71.

Taylor, H. \& Reyes, H. 2012. Self-Efficacy and resilience in Baccalaureate nursing students. International Journal of Nursing Education Scholarship 9: 1-13.

Turner, J. \& Patrick, H. 2008. How does motivation develop and why does it change? Reframing motivation research. Educational Psychologist 43: 119-131.

Usher, E. L. \& Pajares, F. 2008. Sources of self-efficacy in school: Critical review of the literature and future directions. Review of Educational Research 78: 751-796.

Vancouver, J. B. \& Kendall, L. N. 2006. When self-efficacy negatively relates to motivation and performance in learning context. Journal of Applied Psychology 91: 1146-1153.

van der Bijl, J. J. \& Shortridge-Baggett, L. M. 2001. The theory and measurement of the self-efficacy construct. Scholarly inquiry for nursing practice 3: 189-207.

van der Helm, R. 2009. The vision phenomenon: Towards a theoretical underpinning of visions of the future and the process of envisioning. FUTURES 4: 96-104.

Vasquez, N. A. \& Buehler, R. 2007. Seeing future success: Does imagery perspective influence achievement motivation. Personality and Social Psychology Bulletin 33(10): 1392-1405.

Wise, J. B. \& Trunnell, E. P. 2001. The influence of sources of self-efficacy upon efficacy strength. Journal of Sport and Exercise Psychology 23: 268-280.

Yokoyama, S. 2019. Academic self-efficacy and academic performance in online learning: A Mini Review. Frontiers in Psychology 9: 23-41.

Zajacova, A, Lynch, S. M. \& Espenshade, T. J. 2005. Self-efficacy, stress, and academic success in college. Research in Higher Education 46: 677-706.

\section{***}

Arkadiusz Pietluch is a Ph.D. student at the University of Rzeszów, where he currently teaches subjects such as phonetics, phonology, and practical English. His areas of academic interest include bilingualism and the impact of psychological variables on human cognition. 